Orbis Tertius, vol. XXV, nº 32, e181, noviembre 2020-abril 2021. ISSN 1851-7811

Universidad Nacional de La Plata

Facultad de Humanidades y Ciencias de la Educación

Centro de Estudios de Teoría y Crítica Literaria

\title{
Teresa Basile y Miriam Chiani (Comp.), Voces de la violencia: avatares del testimonio en el Cono Sur. La Plata, EDULP, 2020, 390 páginas
}

Enzo Matías Menestrina

Cita sugerida: Menestrina, E. M. (2020).

[Revisión del libro Voces de la violencia: avatares del testimonio en el Cono Sur por T. Basile y M.

Chiani (Comp.)]. Orbis Tertius, 25(32), e181.

https://doi.org/10.24215/18517811e181

El volumen Voces de la violencia: avatares del testimonio en el Cono Sur, publicado recientemente en formato digital por EDULP, concentra las respuestas a la mayoría de las preguntas que uno podría formularse con respecto al testimonio en sí y a propósito de los diferentes modos de lectura en estas escrituras. Este libro es el resultado de los trabajos presentados en el Coloquio "La figura del testigo y los avatares del testimonio. Debates teóricos y representaciones culturales", que tuvo lugar en la Facultad de Humanidades y Ciencias de la Educación de la Universidad Nacional de La Plata los días 17 y 18 de septiembre de 2018. Sus compiladoras, Teresa Basile y Miriam Chiani, apuestan al diálogo entre diversos estudios que indagan acerca de la construcción del pasado reciente y configuran, a la vez que reproducen, las copiosas voces de la violencia en el Cono Sur. En tal sentido, los discursos sobre género, los afectos y la construcción de la identidad son solo algunas de tantas líneas que delimitan los estudios actuales sobre el testimonio al transitar, paso a paso, los inquietantes recovecos de la memoria. Ahora bien, ¿qué lugar ocupa el testimonio en la historia cultural latinoamericana?, ¿es posible hablar de un giro en las escrituras testimoniales o acaso se trata de una segunda reinstalación de estas?

El título del libro resume la operación central de lectura conjunta de los catorce artículos que se reúnen aquí. En tal aspecto, cuestionarse si las voces de la violencia se pueden pensar como giros de un continuum en las escrituras testimoniales, o si se trata de una segunda reinstalación de estas, supone una indagación exhaustiva para pensar cada una de las entradas. Estos “avatares” convocarán las voces del discurso testimonial a partir de un corpus numeroso e incursionarán en su modo de representación. El volumen se encuentra estructurado en tres zonas, además de un extenso y enriquecedor prólogo, que funcionan como "puertas 
de acceso" para su lectura y que, también, responden al modo de interpretar dichos avatares: "Perspectivas teóricas", "Testimonios, espacios y género" y "Segunda generación”.

En la primera parte, "Perspectivas teóricas. De la construcción al desmonte del testimonio", se presentan tres trabajos de carácter teórico-crítico sobre el testimonio provenientes de diferentes ángulos: la filosofía, el psicoanálisis, los estudios culturales y la crítica literaria. El primero, escrito por Ana María Amar Sánchez, aborda los sujetos del testimonio y explora algunas figuras como la del narrador, el testigo y la víctima para articularlas con la figura del lector. La autora revisa las controversias en los postulados de Agamben sobre la impronta del testimonio y revalida críticamente el reciente giro de la figura de "víctima", y su posición en la actualidad, presente en varias publicaciones de las cuales los textos de Philippe Mesnard, La victime écran (2002) y Crítica de la víctima (2017) de Daniele Giglioli son los ejemplos más evidentes que allí se exponen. En "Perspectivas subjetivas sobre el testimonio. Experiencias límite, lenguaje y representación", Susana Kaufman aporta, desde la óptica del psicoanálisis, otra entrada a ciertas cuestiones teóricas sobre el testimonio, en su construcción narrativa en el impacto del trauma en la subjetividad. Por su parte, Susana Rosano lleva a cabo una operación deconstructiva en la medida en que propone un análisis teórico-crítico que va a iluminar el desmantelamiento de cierto modelo "anquilosado" del testimonio latinoamericano, llevado a cabo por María Moreno en Oración. Carta a Vicki y otras elegías políticas, de 2018. Así, Rosano propone leer en detalle los procedimientos que permiten desbaratar las lecturas heroicas y subrayar las estrategias de interpretación. A esta tarea deconstructiva, la autora le suma el aporte de tres libros fundamentales que se abren hacia una memoria crítica de la violencia política: la mirada de Beatriz Sarlo en Tiempo pasado. Cultura de la memoria y giro subjetivo (2005); de Pilar Calveiro, Politica y/o violencia (2007); y de Hugo Vezzetti, Sobre la violencia revolucionaria (2009).

La segunda puerta de acceso titulada "Testimonios, espacios y género" ahonda en cuestiones institucionales más específicas como la prisión, la escena jurídica o el arte y en otros géneros como las cartas, las novelas o el teatro. Este núcleo articula las diferentes miradas para privilegiar el lugar más importe de la agenda cultural en el Cono Sur: el testimonio. El primer artículo es la colaboración de Fernando Reati y Paula Simón: "Cárceles e incomunicación en la última dictadura militar argentina”. En esta interesantísima propuesta, los autores indagan en los testimonios de cartas de la UP1 de Córdoba. El escrito recupera el contexto carcelario y la situación de incomunicabilidad de los presos con el exterior. Los "detenidos especiales" eran un grupo de presos en completo aislamiento que accionan entre la legalidad y la ilegalidad dado que, en el período que comprendía entre 1976 y 1979, se las ingeniaron para comunicarse con sus familiares de forma clandestina a través de "palomas", es decir, papeles envueltos en polietileno u otro material en forma de caramelos. Con esta modalidad se crean lazos entre los presos especiales y los denominados "comunes" en complicidad con los familiares fuera de la cárcel. A modo de ensayo, el escrito recupera y analiza algunas de las cartas. El segundo trabajo pertenece a Claudia Bacci quien recorre, a través de la perspectiva de género, una serie de testimonios producidos en tres escenas diferentes, _ juicio a las Juntas Militares, juicio por la verdad de La Plata y "Archivo Oral” de Memoria Abierta- en las que la reconstrucción del parentesco y las marcas del género emergen de manera persistente en la reelaboración de genealogías de distintas generaciones enlazadas por las voces de la violencia y el terror de la dictadura. Por otro lado, remarcar el modo en que se vinculan diversas modalidades temporales con distintas prácticas teatrales en las piezas de Lola Arias es lo que se propone Cecilia González. La autora analiza cómo las puestas en escena intermediales de Lola Arias, marcadas por una circulación entre ficcionalización y factualidad, conjugan tres variantes con diversos efectos: el modo testimonial-documental que convoca la temporalidad de la catástrofe, la performance teatral o musical, y el reenactment que subraya la distancia temporal entre el acontecimiento catástrofe y la reelaboración presente. Asimismo, Rodrigo Montenegro en "Potencias políticas de la ficción" propone una lectura original de Los pichiciegos (1983) de Fogwill para analizar la representación contracultural del testimonio, o mejor, un texto que adopta la máscara del testimonio para desplegar una versión distorsiva, especulativa de la guerra y sus consecuencias en la sociedad argentina a partir de estrategias literarias que saturan el nivel discursivo y 
logran recorrer otros circuitos. Montenegro interpreta los diferentes objetivos, niveles y alcances con los que Fogwill explota la ficción testimonial. El trabajo de María Laura de Arriba, "Patricio Guzmán. Una memoria obstinada en la construcción del archivo chileno", propone una lectura de Nostalgia de la luz (2010) y El botón de nácar (2015), basada en las ideas de Derrida sobre la noción de archivo para detenerse en una reflexión sobre la dimensión de lo póstumo o del porvenir y el análisis de El botón de nácar es guiado por la idea de Didi-Huberman de memoria como montaje.

En la última zona del volumen, "Segunda generación", se reúnen los artículos que se encuadran en la producción de los "hijos de" las víctimas del terrorismo de Estado como así también los lazos que pueden establecerse entre los textos publicados por coetáneos o "prójimos". En el primer trabajo de esta sección Ramón Inama hace dialogar el texto "Tiempo futuro" de Axat y "Cuando las imágenes tocan el aire" de DidiHuberman para identificar las marcas sobresalientes de los testimonios con implicancias a nivel personal. En "Del testimonio a la novela familiar. La narrativa de Laura Alcoba", Victoria Daona analiza el deslizamiento desde lo testimonial hacia la ficción, y desde el testigo hacia el personaje. Daona recupera los postulados de Rosana Nofal e indica que Laura Alcoba recrea una "novela familiar", entendida como una trayectoria, en la que ella y sus padres son protagonistas. Este artículo permite comprender la particular construcción identitaria que el sujeto exiliado hace de su propia experiencia en la narración. En tercer lugar, el texto "Explorar los bordes" de María A. Semilla Durán analiza Veintiocho. Sobre la desaparición, de Eugenia Guevara como un texto peculiar, no sólo por un contenido que se desmarca de la mayoría de los relatos de los hijos en función de los comportamientos específicos de la madre desaparecida, sino también por una estructura en cajas chinas que es funcional al itinerario clásico de la búsqueda, dimensión investigativa del texto, y a la puesta en escena de las sucesivas revelaciones, documentos ocultos y enigmas que se entretejen. En "El testimonio y la experiencia de la muerte", Eugenia Straccali despliega los rasgos del sujeto ficcional/ testimonial que Raúl González Tuñón configura en una serie de textos pertenecientes a distintos contextos históricos: La rosa blindada (1935) y La Muerte en Madrid (1936), Himno de pólvora (1943) y Demanda contra el olvido (1968). A través de una óptica poética, la autora focaliza en cómo las modulaciones de una particular configuración vinculada al testimonio - donde el sujeto no solo observa, sino que es partícipe de los hechos y es garante de la experiencia inenarrable de la muerte- inauguran una línea en la literatura argentina retomada por Juan Gelman y Julián Axat. Luego, Teresa Basile ("El testimonio y sus fugas hacia la ciencia ficción en la narrativa de HIJOS/AS”) postula al testimonio, en las narrativas de hijos, como el punto del que ellos parten, es decir, el discurso predominante durante la primera etapa: autoriza las voces y exhibe los intereses de HIJOS. Basile indica que se constituye así en el género matriz que en una segunda etapa adviene cuando esta generación ya ha adquirido visibilidad política y cultural a través de su producción artística y la aparición de HIJOS. Señala que se produce un desvío e interferencia (sin abandonar la pulsión testimonial) con otros discursos, géneros, estéticas. ¿Cómo lo analiza? A propósito de las estrategias de fuga del testimonio por parte de la segunda generación, Basile sugiere una lectura que interpela sobre el desvío hacia la ciencia ficción a partir de la revisión de dos textos: el cuento "2073" (2014), de Félix Bruzzone, y Soy un bravo piloto de la nueva China (2011) de Ernesto Semán. El último estudio se titula "Prójimos". Se trata de una colaboración de Miriam Chiani y Silvina Sánchez, en la que indagan sobre la narrativa de autores nacidos en los ' 60 y los '70 y publicados a partir de mediados del 2000, que retoman el contexto del terrorismo de estado o establecen vínculos con el genocidio desde diferentes perspectivas. El corpus que trabajan está compuesto por: Chicos que vuelven de Mariana Enríquez, Una misma noche de Leopoldo Brizuela, Historia del llanto, Historia del pelo e Historia del dinero de Alan Pauls, entre otros. Lo interesante de la propuesta es que estos textos evidencian algunos cambios en relación a novelas publicadas antes sobre esta temática, como Villa (1996) de Luis Gusmán o Dos veces junio de Martín Kohan. De este modo, Chiani y Sanchez identifican en esos textos dos dinámicas cuyas ópticas se interpelan: la del entrever (ver de lejos, de manera confusa o imprecisa); y la de la contigüidad y superposición (fundir, hacer repercutir la violencia de los '70 en otras diferentes formas de violencia). 
Puede decirse que el volumen Voces de la violencia es el resultado del frondoso y ramificado trayecto de un grupo de investigación comprometido con la labor de proyectar nuevas miradas en lo concerniente a los diversos modos de leer y repensar los testimonios, ya sea desde la violencia, desde el género o desde el archivo. En efecto, los trabajos que reúne este libro son vasos comunicantes pero también son las piezas esenciales que componen los estudios de la memoria para enlazar, o quizás, intentar restaurar las numerosas perspectivas sobre el testimonio en el Cono Sur y así propagar las voces que acechan violentamente a la historia reciente. 